Check for updates

Cite this: RSC Adv., 2019, 9, 3367

Received 1st October 2018

Accepted 29th December 2018

DOI: $10.1039 / c 8 r a 08143 c$

rsc.li/rsc-advances

\section{Removal of As(III) and As(v) from water using green, silica-based ceramic hollow fibre membranes via direct contact membrane distillation}

\author{
Siti Khadijah Hubadillah, ${ }^{a}$ Mohd Hafiz Dzarfan Othman, (D) *a Siti Hamimah Sheikh \\ Abdul Kadir, ${ }^{\text {b }}$ Mohd Riduan Jamalludin, ${ }^{c}$ Zawati Harun, ${ }^{d}$ Mohd Haiqal Abd Aziz, ${ }^{a}$ \\ Mukhlis A. Rahman, ${ }^{a}$ Juhana Jaafar, ${ }^{a}$ Mikihiro Nomura, ${ }^{e}$ Sawao Honda, ${ }^{f}$ Yuji Iwamoto ${ }^{f}$ \\ and Hamzah Fansurig
}

\begin{abstract}
Arsenite $[\mathrm{As}(\mathrm{III})]$ and arsenate $[\mathrm{As}(\mathrm{V})]$ removal by direct contact membrane distillation (DCMD) using novel hydrophobic green, silica-based ceramic hollow fibre membranes derived from agricultural rice husk was investigated in this work. The green ceramic hollow fibre membranes were prepared from amorphous (ASHFM) and crystalline (CSHFM) silica-based rice husk ash and modified to be hydrophobic via immersion fluoroalkylsilane (FAS) grafting of $1 \mathrm{H}, 1 \mathrm{H}, 2 \mathrm{H}, 2 \mathrm{H}$-perfluorodecyltriethoxysilane. Superhydrophobic contact angle values up to $157^{\circ}$ and $161^{\circ}$ were obtained for ASHFM and CSHFM, respectively. Remarkably, the membrane surface morphology mimicked a look-alike lotus-leaf structure with decrement in pore size after grafting via the silane agent for both membranes. The effect of arsenic $\mathrm{pH}(3-11)$, arsenic concentration (1-1000 ppm) and feed temperature $\left(50-80{ }^{\circ} \mathrm{C}\right)$ were studied and it was found that feed temperature had a significant effect on the permeate flux. The hydrophobic CSHFM, with a flux of $50.4 \mathrm{~kg} \mathrm{~m}^{-2} \mathrm{~h}^{-1}$ for As(III) and $51.3 \mathrm{~kg} \mathrm{~m}^{-2} \mathrm{~h}^{-1}$ for As(v), was found to be the best of the tested membranes. In fact, this membrane can reject arsenic to the maximum contaminant level (MCL) limit of 10 ppb under any conditions, and no swelling mechanism of the membranes was observed after testing for 4 hours.
\end{abstract}

\section{Introduction}

Arsenic is regarded as one of the most toxic heavy metals and the largest mass poisoning agent in the world, being widely present in the environment in rocks, soils and groundwater. ${ }^{1,2}$ In fact, it has been classified as a Group 1 human carcinogen by the International Agency for Research on Cancer (IARC). ${ }^{3}$ Arsenic is the $20^{\text {th }}$ most abundant element in the Earth's crust,

${ }^{a}$ Advanced Membrane Technology Research Centre (AMTEC), Universiti Teknologi Malaysia, 81310 Skudai, Johor, Malaysia.E-mail: hafiz@petroleum.utm.my; Fax: +607 5535925; Tel: +6075535592

${ }^{b}$ Institute of Molecular Medicine and Biotechnology, Faculty of Medicine, Universiti Teknologi MARA Sungai Buloh Campus, Cawangan Selangor, Jalan Hospital, 47000 Sungai Buloh, Selangor, Malaysia

'Faculty of Engineering Technology, Universiti Malaysia Perlis (UniMAP), Kampus UniCITI Alam, Sungai Chuchuh, Padang Besar, 02100 Perlis, Malaysia

${ }^{d}$ Advanced Materials and Manufacturing Centre (AMMC), Faculty of Mechanical and Manufacturing Engineering, Universiti Tun Hussein Onn Malaysia, 86400 Parit Raja, Batu Pahat, Johor Darul Takzim, Malaysia

${ }^{e}$ Department of Applied Chemistry, Shibaura Institute of Technology, 3-7-5 Toyosu, Koto-ku, Tokyo 135-8548, Japan

${ }^{f}$ Department of Environmental and Materials Engineering, Nagoya Institute of Technology, Gakiso-cho, Showa-ku, Nagoya 466-8555, Japan

${ }^{g}$ Department of Chemistry, Faculty of Science, Institut Teknologi Sepuluh Nopember, 60111, Kampus ITS Sukolilo, Indonesia the $14^{\text {th }}$ in seawater and the $12^{\text {th }}$ most abundant element in the human body. ${ }^{4}$ There are two forms of arsenic, namely arsenite $[\operatorname{As}(\mathrm{III})]$ and arsenate $[\operatorname{As}(\mathrm{V})]$. In general, arsenic is found in trace amounts in both surface water and groundwater, but in higher concentration levels in groundwater. In view of this, the literature reveals that arsenic contamination can cause serious human health problems, such as long-term cancer. ${ }^{5}$

For more than 100 years, many technologies have been introduced for the removal of arsenic from water, including precipitation, coagulation, electrocoagulation, reverse osmosis, electrodialysis, adsorption, ion exchange, and membrane filtration. Conventionally, coagulation and flocculation are among the most common methods of arsenic removal. The most common material for coagulant is iron. However, this material does not ensure total compliance for various metals, especially arsenic, since hydroxide does not completely precipitate at a single $\mathrm{pH}$. Adsorption has evolved as the most promising and well-known method for effective removal of As(III) and $\operatorname{As}(v)$ from water, ${ }^{6}$ but it has been reported that adsorption also shows some drawbacks that need urgent modification. Among the drawbacks are: (i) limitations to transferring the technology to market due to a lack of excellent adsorbents with high adsorption capacity and lack of availability of a commercial 
scale column; and (ii) the adsorption capabilities of different types of water pollutants.

Membrane distillation (MD) is a recent technology that has received much attention for water purification, including desalination and heavy metal removal. In 2008, MD was first applied to arsenic removal and achieved $100 \%$ rejection of both $\operatorname{As}(\mathrm{III})$ and $\mathrm{As}(\mathrm{V}) .^{7}$ In membrane distillation systems, only water vapour is allowed to pass through a microporous hydrophobic membrane. The water vapour transport is thermally driven by a vapour pressure difference between the two sides of the membrane's pores. ${ }^{8}$ This water vapour permeation is also referred to as permeate flux. In MD, a lower permeate flux is commonly observed due to the vapour transport through the hydrophobic membrane used in the system. Unlike other methods, such as reverse osmosis membranes, MD has many unique features such as low operating pressure and porous membrane structure. Remarkably, high permeate flux can be obtained by MD due to the porous structure, with very low operating pressure.

Of all types of MD configuration, direct contact membrane distillation (DCMD) seems to be the first-line choice over other configurations. This is due to the fact that DCMD does not need an external condenser and so is very suitable for water-based applications. ${ }^{9}$ In addition, DCMD has the simplest MD configuration to set up..$^{10}$ In a DCMD system, the hot feed solution is in direct contact with the hot hydrophobic membrane side surface; thus, evaporation takes place at the feed membrane surface. ${ }^{11}$ Hydrophobic polymeric membranes, such as polyvinylidene fluoride (PVDF), polytetrafluoroethylene (PTFE) and polypropylene (PP), are commonly employed for MD because of their low surface energy and high hydrophobicity. However, polymers have disadvantages in that they are unable to act in harsh conditions such as high temperature and high chemical resistance, which are crucial properties for membranes in MD. ${ }^{15-19}$

Ceramic membranes are able to tackle this problem, as they can withstand harsh conditions due to their excellent mechanical stability, chemical stability and thermal resistance. ${ }^{20-22}$ In general, alumina is the most common material for fabrication of ceramic membranes. ${ }^{23-25}$ Unfortunately, ceramic membranes from alumina show some drawbacks and dramatic alterations due to high sintering temperature up to $1500{ }^{\circ} \mathrm{C}$ to reach a compromise between mechanical strength and porosity using micron-sized alumina powder. ${ }^{20,26}$ This high sintering temperature, in addition to the high cost of the alumina powder itself, makes these ceramic membranes extremely expensive. In addition, when a high sintering temperature is used, the fabrication process will be prolonged. Nevertheless, these ceramic membranes possess hydrophilicity behaviour that inhibits their application in membrane distillation systems.

Realising the huge potential that is offered by ceramic membranes, therefore, alternative ceramic material from natural resources, such as clays, ashes from agricultural waste and animal bone waste, have recently been used as new materials for the fabrication of alternative ceramic membranes. ${ }^{26-29}$ From our previous work, ${ }^{30}$ a ceramic hollow fibre membrane was successfully prepared from amorphous and crystalline silica derived from rice husk waste, denoted as ASHFM and CSHFM, at a content of $37.5 \mathrm{wt} \%$ and a sintering temperature of $1200{ }^{\circ} \mathrm{C}$. The most significant result was that both of these membranes showed different pore sizes, with values of $2.35 \mu \mathrm{m}$ and $1.43 \mu \mathrm{m}$ for ASHFM and CSHFM, respectively. Comparing the respective pore sizes, therefore, it is interesting to study the effect of the different membrane pore size on performance in the DCMD system. In this study, the membranes were modified to be hydrophobic via fluoroalkylsilane (FAS) grafting and are denoted as h-ASHFM and h-CSHFM for amorphous and crystalline silica, respectively. FASs are a group of compounds that can be used to efficiently create hydrophobic character for different surfaces. The grafting process can be performed by a reaction between $-\mathrm{OH}$ surface groups of the ceramic and the ethoxy groups $(-\mathrm{O}-\mathrm{Et})$ present in the organosilane compounds. Accordingly, an experimental study was performed under various conditions, such as $\mathrm{pH}$, concentration and feed temperature, in order to test the arsenic rejection efficiency of the modified membrane in the DCMD process.

\section{Experimental}

\subsection{Materials}

Green, silica-based ceramic hollow fibre membranes prepared from rice husk waste were used from our previous work. ${ }^{30}$ For surface modification through FAS grafting, $1 \mathrm{H}, 1 \mathrm{H}, 2 \mathrm{H}, 2 \mathrm{H}$-perfluorodecyltriethoxysilane (97\%), with a chemical formula of $\mathrm{C}_{8} \mathrm{~F}_{17} \mathrm{C}_{2} \mathrm{H}_{4} \mathrm{Si}\left(\mathrm{OC}_{2} \mathrm{H}_{5}\right)_{3}$, was used as the grafting agent (SigmaAldrich, USA) and ethanol (Merck, Germany) as solvent. The stock solutions of $\operatorname{As}(\mathrm{III})$ and $\operatorname{As}(\mathrm{v})$ were prepared from sodium $($ meta $)$ arsenite $\left(\mathrm{NaAsO}_{2}\right)$ and sodium arsenate dibasic heptahydrate $\left(\mathrm{Na}_{2} \mathrm{HAsO}_{4} \cdot 7 \mathrm{H}_{2} \mathrm{O}\right)$, respectively, at a concentration of $1000 \mathrm{ppm}$. $\mathrm{HCl}$ and $\mathrm{NaOH}$ solutions $\left(0.1 \mathrm{~mol} \mathrm{~L}^{-1}\right)$ were used for $\mathrm{pH}$ adjustment.

\subsection{Hydrophobization of ASHFM and CSHFM}

The hydrophobization of ASHFM and CSHFM were conducted using the immersion-grafted technique. Prior to immersion, ceramic hollow fibre membranes were immersed in a solution containing ethanol and water in a ratio of $1: 2$, respectively, for 24 hours to allow hydroxylation. After this immersion, ceramic hollow fibre membranes were immersed in the grafting solution, which was prepared by mixing $2 \mathrm{wt} \%$ of FAS solution in ethanol at room temperature. The immersion time was set at 24 hours to allow complete reaction of hydroxyl groups between the membrane surface and FAS solution. Thereafter, the grafted membranes were rinsed to remove unreacted FAS on the membrane surface. Finally, the grafted, ceramic hollow fibre membranes were dried at $100{ }^{\circ} \mathrm{C}$ in an oven, overnight.

\subsection{Characterization}

The surface and cross-sectional morphology of the fabricated ceramic hollow fibre membranes (KHFMs) were measured using Scanning Electron Microscopy (SEM) (TM 3000, Hitachi). The contact angle of the ceramic hollow fibre membrane was measured at the surface before and after hydrophobization by 
the sessile drop technique using a goniometer (Model: OCA 15EC, Dataphysics). Mercury intrusion porosimetry (MIP, AutoPore IV, Micromeritics, USA) was used to measure the porosity and pore size distribution of the KHFMs prepared at different sintering temperatures and addition of pore agents. The KHFMs were broken into pieces and transferred to the 5 $\mathrm{cm}^{3}$ penetrometer sample holder (Micrometeritics, USA) which was then pressurized from 38.6 to $4.2 \times 10^{6}$ mbar for mercury intrusion. ${ }^{31}$ In this study, liquid entry pressure (LEPw) was used to measure the wettability properties of the grafted ceramic hollow fibre membranes. Distilled water flowed into the lumen side of the hollow fibre membranes using a diaphragm pump. The pressure was slowly increased, at 0.5 bar intervals, and the pressure at which the first water droplets appeared on the shell side surface of the hollow fibre was recorded as the LEPw. ${ }^{\mathbf{1 3 , 1 4}}$

\subsection{DCMD experiment}

DCMD tests were carried out on a laboratory-scale setup, as illustrated in Fig. 1. The setup consisted of two thermostated cycles, hot and cold, that were connected to a membrane module. In the module, seven hollow fibres with a nominal surface area of $0.0354 \mathrm{~m}^{2}$ were assembled. The system was designed to have two circulating streams, i.e., a hot feed stream flowing on the membrane shell side and a cold stream on the lumen side. Arsenic synthetic wastewater was employed as the feed on the hot side and deionized water flowed on the cold side. The temperatures of the hot and cold streams were controlled using a coiled heater (830, PROTECH) and chiller (S\&A CW-5000), respectively. There were two thermometers (Extech 392050) equipped on the inlets and outlets of the feed and permeate sides, respectively. Meanwhile, the cross-flow velocities of both hot and cold streams were set at 0.7 LPM and 0.5 LPM, respectively. In this study, As(III) and As(v) were placed in the feed reservoir and the feed temperature was varied from 40 to $80{ }^{\circ} \mathrm{C}$, whereas the permeate was distilled water and the temperature was maintained at $10^{\circ} \mathrm{C}$. The concentrations of As(III) and As(v) were set at 1, 50, 100, 500, and $1000 \mathrm{ppm}$ at a pH of 7.5 to study the effect of arsenic concentration. Then, the effects with $\mathrm{pH}$ varying from 3 to 11 were also studied. The weight of the cold water tank was measured by a weighing balance (model WA-K, WJ) and the permeate flux, $J_{\mathrm{V}}\left(\mathrm{kg} \mathrm{m}^{-2}\right.$ $\mathrm{h}^{-1}$ ) was calculated using eqn (1): ${ }^{11}$

$$
J_{\mathrm{V}}=\frac{\Delta W}{A \Delta t}
$$

where $\Delta W(\mathrm{~kg})$ is the increase in weight of the cold tank over a predetermined time $t(\mathrm{~h})$ and $A\left(0.0354 \mathrm{~m}^{2}\right)$ is the effective membrane area.

The arsenic rejection, $R(\%)$, was calculated using eqn (2): ${ }^{11}$

$$
R(\%)=\left(1-\frac{C_{\mathrm{P}}}{C_{\mathrm{F}}}\right) \times 100 \%
$$

where $C_{\mathrm{P}}$ and $C_{\mathrm{F}}$ are the permeate and feed concentration (ppm), respectively, measured by the graphite furnace absorption spectrometer (PerkinElmer system SIMAA 6000).

\section{Results and discussion}

\subsection{Membrane characterization}

In our previous work, ${ }^{30}$ the characteristics of ceramic hollow fibre membranes from amorphous rice husk ash (ASHFM) and crystalline rice husk ash (CSHFM) prepared via the phase inversion and sintering technique were described. As discussed, the effect of a sintering temperature ranging from $1200{ }^{\circ} \mathrm{C}$ to $1400{ }^{\circ} \mathrm{C}$ showed no significant change in membrane properties such as pore size and mechanical strength. It was also found that increasing the sintering temperature up to $1300{ }^{\circ} \mathrm{C}$ led to membrane melting.

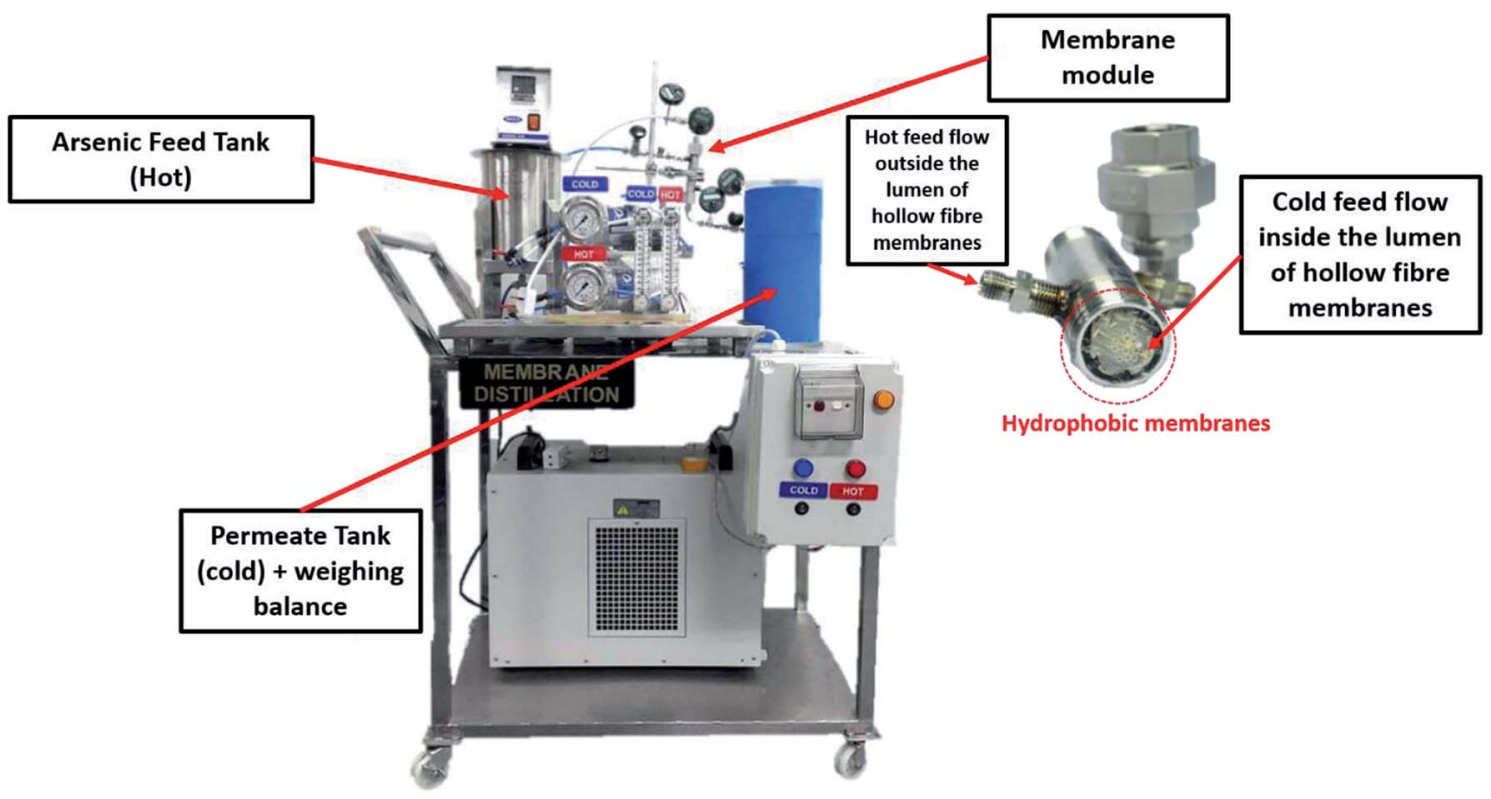

Fig. 1 Laboratory-scale DCMD experimental setup. 
Therefore, a sintering temperature of $1200{ }^{\circ} \mathrm{C}$ is the optimum temperature for both ASHFM and CSHFM. Herein, both ASHFM and CSHFM sintered at $1200^{\circ} \mathrm{C}$ were modified through FAS silane grafting. Fig. 2 shows the outer surface morphologies of ASHFM, CSHFM, h-ASHFM and h-CSHFM, before and after modification. Interestingly, it was observed that at higher magnification the SEM images revealed a look-alike lotus-leaf structure by showing nodule formation on both h-ASHFM and h-CSHFM surfaces. As stated by Fritsch et $a l .,^{32}$ the nodule structure on the lotus leaf provides a rougher surface and induces water repellent behaviour. Elsewhere, these nodule structures have been described as bumps and lumps. ${ }^{33}$ The results herein are in contrast to those obtained from previous studies. For example, Abdulhameed et $a l^{34}$ modified ceramic hollow fibre membranes prepared from kaolin and alumina and found no significant change in the surface SEM image of the pristine and the modified membrane. Picard et al. ${ }^{35}$ also modified ceramic membranes from zirconia with an FAS agent and found no significant change in the modified membrane. This is probably due to the different ceramic material (silica-based rice husk ash) to which the FAS is applied. As stated by Aissaoui et al. ${ }^{36}$ the most common route of functionalization is to attach alkylsilane through formation of $\mathrm{Si}-\mathrm{O}-\mathrm{Si}$ bonds between the silanol groups present on the oxidized silicon surface and the hydrolysed organosilane molecules. As a consequence, silanes are adsorbed to the ASHFM and CSHFM surface through hydrogenbonding interactions, with subsequent condensation and lateral reactions generating siloxane structure. This is explained in our previous work, ${ }^{10}$ where it is believed that the mimicked lotus-leaf structure on the surface of both h-ASHFM and h-CSHFM were formed as a result of various interfacial processes such as covalent binding to the surface, lateral polymerization of adsorbed silanes and three-dimensional polymerization.

The macrostructure of the modified membrane is further demonstrated by comparison of the mercury intrusion data, as
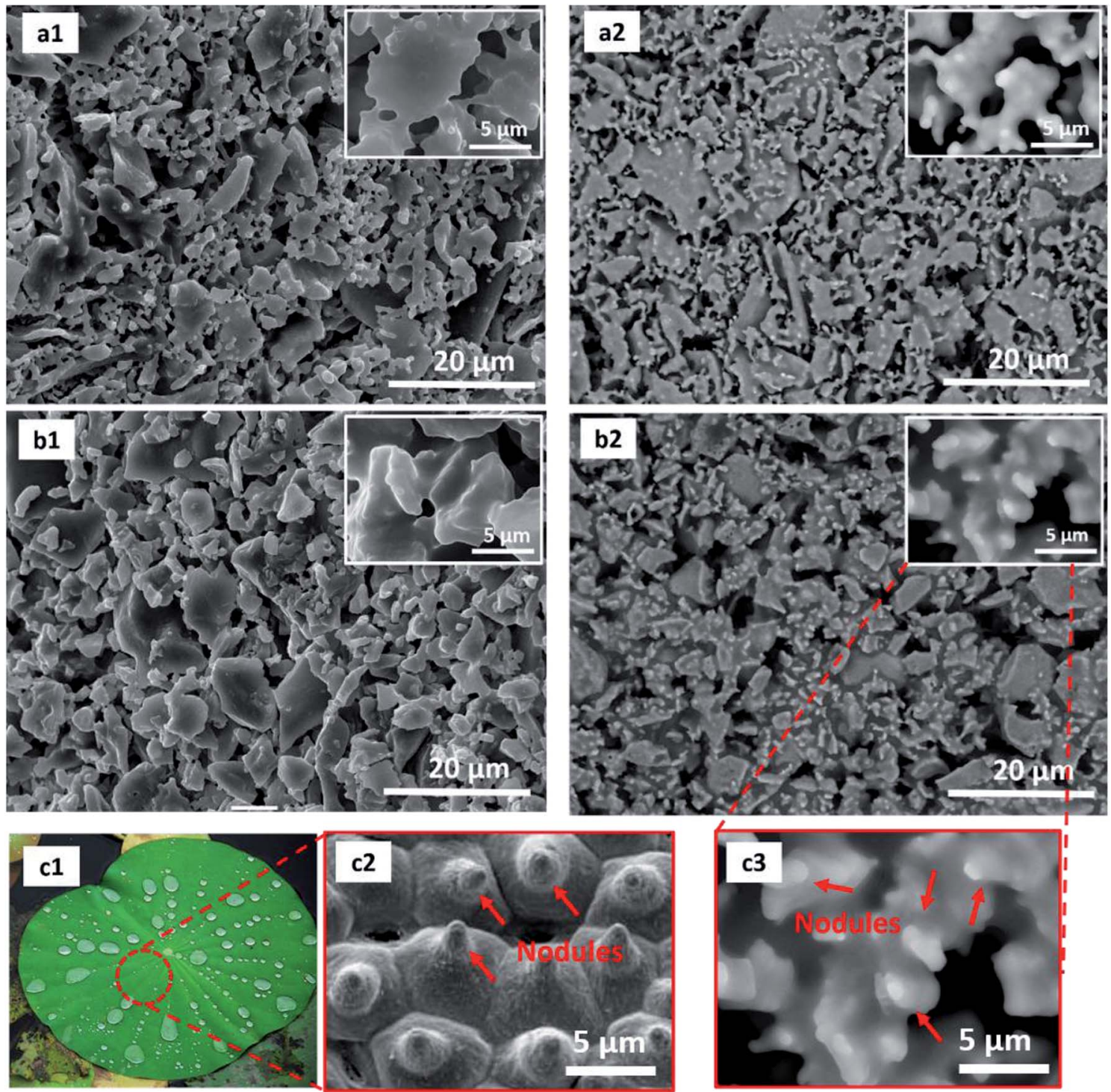

Fig. 2 SEM image of (a1) ASHFM, (a2) h-ASHFM, (b1) CSHFM, (b2) h-CSHFM; ${ }^{10}$ (c1) lotus leaf photographic image; SEM image of (c2) lotus leaf and (c3) high magnification of h-CSHFM. 


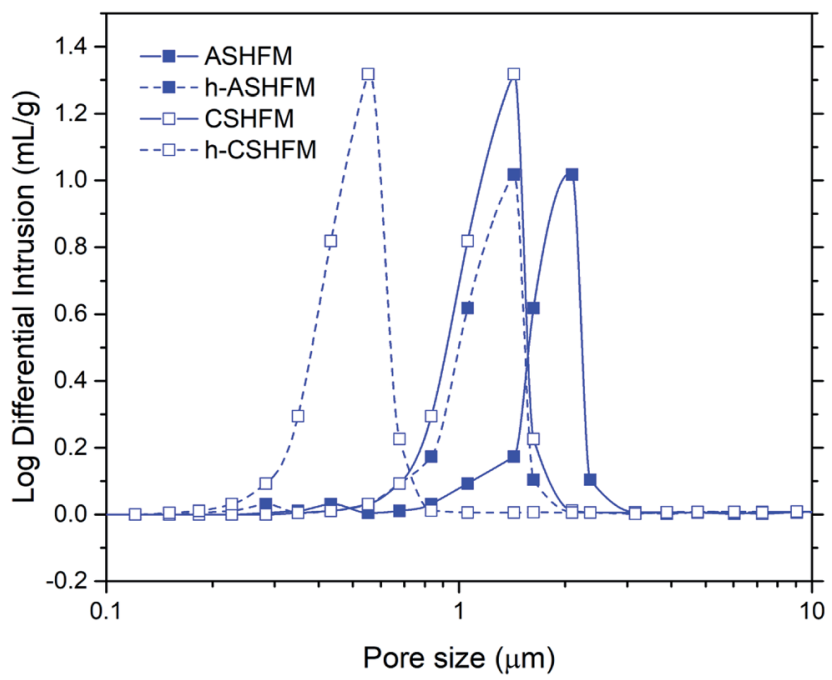

Fig. 3 Pore size distribution of ASHFM, h-ASHFM, CSHFM and hCSHFM.

shown in Fig. 3. According to the data obtained, single pores have been recognised in all membranes. Peaks at approximately $2.35 \mu \mathrm{m}$ and $1.43 \mu \mathrm{m}$ represent ASHFM and CSHFM, respectively. It is interesting to note that the peaks shifted to smaller values, of $1.21 \mu \mathrm{m}$ and $0.54 \mu \mathrm{m}$, respectively, after being modified to be hydrophobic. This agrees with the SEM images discussed previously. This phenomenon can be explained by the FAS molecules being bonded to the surface of the green, ceramic membrane through polymerization, thus forming a polymer layer on the surface that reduces the pore sizes. ${ }^{34}$ Simultaneously, the liquid entry pressure (LEPw) for these membranes was recorded as 0.5 bar and 1 bar for h-ASHFM and h-CSHFM, respectively, compared with 0 bar for non-grafted membranes. Another interesting finding is the significant increase in the contact angle value from superhydrophilic $\left(0^{\circ}\right)$, for both ASHFM and CSHFM, to superhydrophobic, with values of $157^{\circ}$ and $161^{\circ}$ for h-ASHFM and h-CSHFM, respectively. Such data indicate that the ceramic membrane can be easily modified to be superhydrophobic for membrane distillation applications.

\subsection{Effect of $\mathrm{pH}$ of arsenic solution}

Experiments at different $\mathrm{pH}$ of arsenic feed, ranging from $\mathrm{pH} 3$ to $\mathrm{pH} 11$, were performed and are presented in Fig. 4 and 5 for $\operatorname{As}(\mathrm{III})$ and $\operatorname{As}(\mathrm{V})$, respectively. Overall, it was observed that the effect of $\mathrm{pH}$ is not noticeable for both As(III) and As(v) performance, especially with regard to arsenic rejection performance. Although there is a slight difference for permeate flux performance, the difference is very small. For h-ASHFM, the permeate flux varied from 52.5 to $54.7 \mathrm{~kg} \mathrm{~m}^{-2} \mathrm{~h}^{-1}$ for $\mathrm{As}(\mathrm{III})$ and 51.6 to $55.8 \mathrm{~kg} \mathrm{~m}^{-2} \mathrm{~h}^{-1}$ for As(v). Meanwhile, a gradual decrease in permeate water flux is observed for h-CSHFM, with values in the range $41.3-42.3 \mathrm{~kg} \mathrm{~m}^{-2} \mathrm{~h}^{-1}$ for As(III) and $41.3-43.3 \mathrm{~kg} \mathrm{~m}^{-2} \mathrm{~h}^{-1}$ for As(v). This suggested that the higher permeate flux obtained for h-ASHFM was due to a larger membrane pore size than that of h-CSHFM. This agreed with the result from literature where

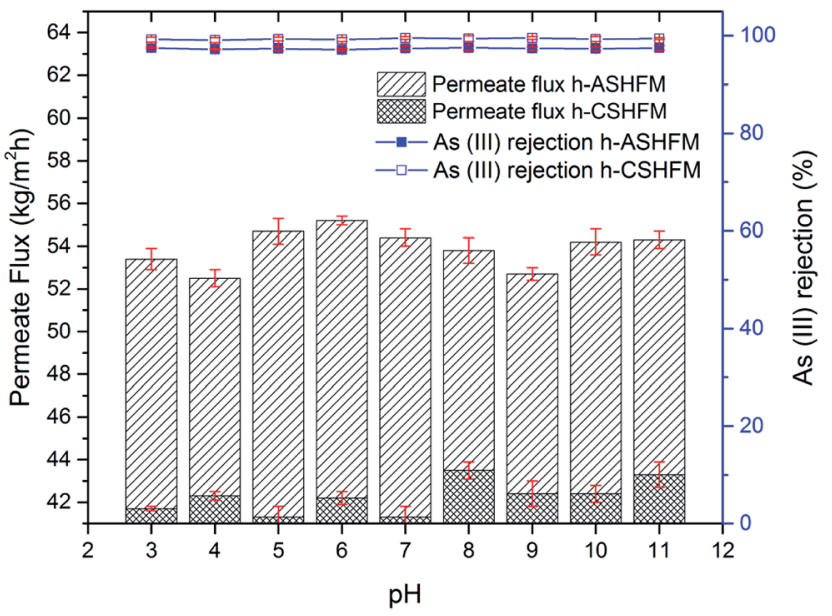

Fig. 4 Effect of $\mathrm{pH}$ on the permeate flux and As(III) rejection of $\mathrm{h}$ ASHFM and h-CSHFM sintered at $1200^{\circ} \mathrm{C}$, during the DCMD process (number of samples, $n=3$; arsenic concentration $=1$ ppm; arsenic feed temperature $=60^{\circ} \mathrm{C}$ ).

the permeate flux decreased with increasing sintering temperature attributed to the decrease of membrane pore size. ${ }^{11}$ This phenomenon has also been described in detail by El-Bourawi et al. ${ }^{12}$ where the permeate flux increases with increasing membrane pore size. As a consequence, this result proves experimentally that the effect of arsenic $\mathrm{pH}$ is insignificant for permeate flux of the DCMD process for both h-ASHFM and $\mathrm{h}$ CSHFM.

Although $\mathrm{pH}$ did not influence the permeate flux of $\mathrm{h}$ ASHFM and h-CSHFM, it is, however, important to note the difference in As(III) and As(v) rejection for both h-ASHFM and hCSHFM. Specifically, the rejection of $\mathrm{As}(\mathrm{III})$ and $\mathrm{As}(\mathrm{v})$ by $\mathrm{h}-$ ASHFM ranges from 97.1 to $97.5 \%$ and 96.8 to $97.7 \%$, respectively. Whereas, h-CSHFM induces a higher rejection for As(III) and $\mathrm{As}(\mathrm{v})$, with values ranging from 99.1 to $99.5 \%$ and 99.3 to

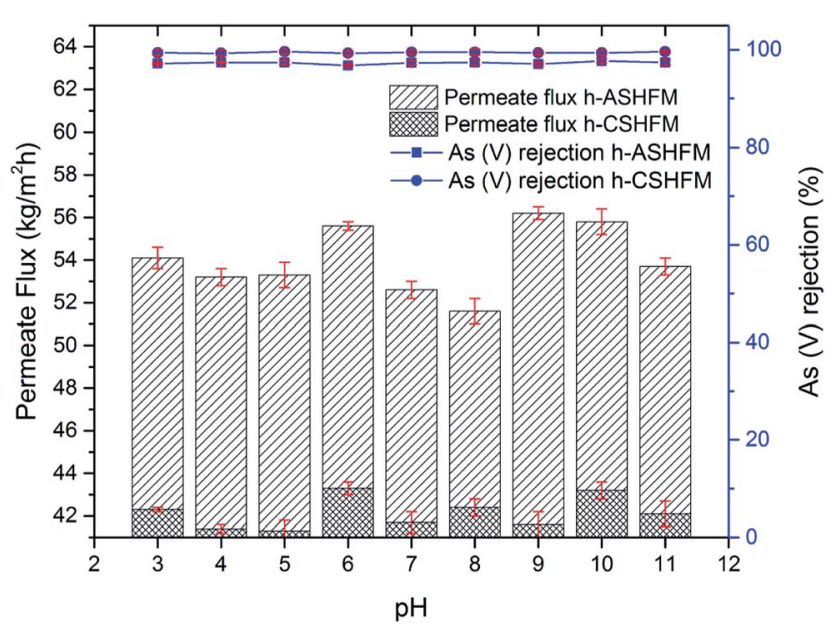

Fig. 5 Effect of $\mathrm{pH}$ on the permeate flux and $\mathrm{As}(\mathrm{V})$ rejection of $\mathrm{h}$ ASHFM and h-CSHFM sintered at $1200^{\circ} \mathrm{C}$, during the DCMD process (number of samples, $n=3$; arsenic concentration $=1$ ppm; arsenic feed temperature $=60^{\circ} \mathrm{C}$ ). 
99.6\%, respectively. Considering the MCL of $10 \mathrm{ppb}$ previously noted, this result, therefore, indicates that h-ASHFM could not reject both $\mathrm{As}(\mathrm{III})$ and $\mathrm{As}(\mathrm{v})$ to the required MCL. For example, a $97.1 \%$ rejection of $\mathrm{As}(\mathrm{III})$ results in the permeate flux containing $29 \mathrm{ppb}$ of arsenic. Thus, this result demonstrates experimentally the importance of membrane pore size in DCMD performance (both permeate flux and rejection). According to Alkhudhiri et al., a large pore size is required for high permeate flux in the MD process; whereas, smaller pore size is needed to avoid liquid penetration. ${ }^{37}$ As a consequence, the optimum membrane pore size should be measured. In line with this hypothesis, the present study found an optimum membrane pore size should be in the range $0.1-0.5 \mu \mathrm{m}$ for use in DCMD processes for arsenic removal from wastewater.

\subsection{Effect of arsenic concentration}

To further investigate the impact of membrane pore size between h-ASHFM and h-CSHFM, an experiment was carried out under different arsenic concentrations. Fig. 6 and 7 show the permeate flux and arsenic rejection for h-ASHFM and hCSHFM at As(III) and As(v) concentrations ranging from 1 to $1000 \mathrm{ppm}$. As observed, a gradual decrease in permeate flux is observed for both h-ASHFM and h-CSHFM. The permeate flux decreased by about $10 \%$ and $16 \%$ when the As(III) concentration in the feed tank increased from 1 ppm to $1000 \mathrm{ppm}$, for hASHFM and h-CSHFM, respectively. A similar trend in permeate flux decrease was observed in the case of As(v). In line with the hypothesis, increasing concentration decreases the permeate flux which is attributed to the decrease of the water vapor pressure and driving force during the MD process. ${ }^{38}$ At this stage, there is also a contribution from the concentration polarization effect. This mechanism has been explained as: ${ }^{39}$

$$
\xi_{\mathrm{s}}=\frac{C_{\mathrm{m}, \mathrm{f}}}{C_{\mathrm{b}, \mathrm{f}}}
$$

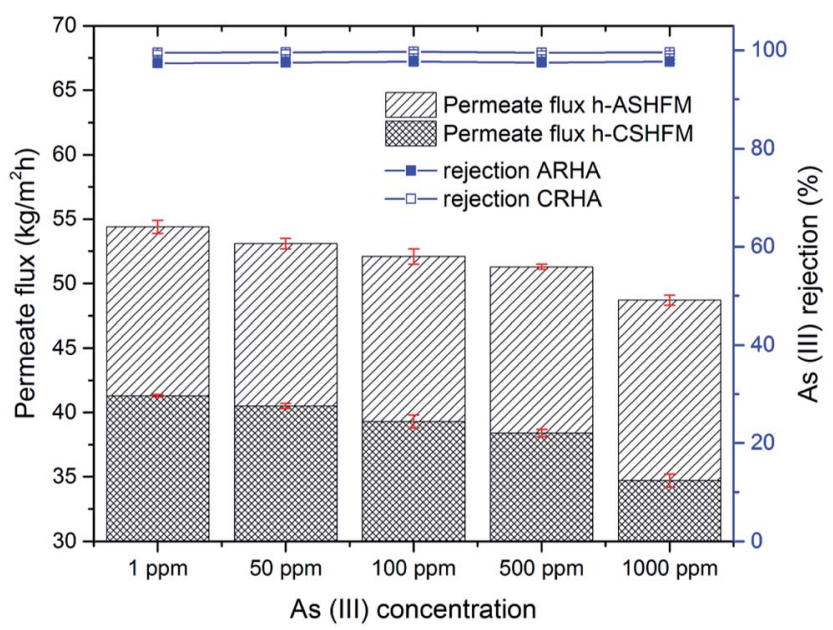

Fig. 6 Effect of As(III) concentration on the permeate flux and As(III) rejection of $\mathrm{h}$-ASHFM and $\mathrm{h}-\mathrm{CSHFM}$ sintered at $1200{ }^{\circ} \mathrm{C}$, during the DCMD process (number of samples, $n=3$; arsenic feed temperature $=$ $60^{\circ} \mathrm{C}$; arsenic $\mathrm{pH}=7.45$ ).

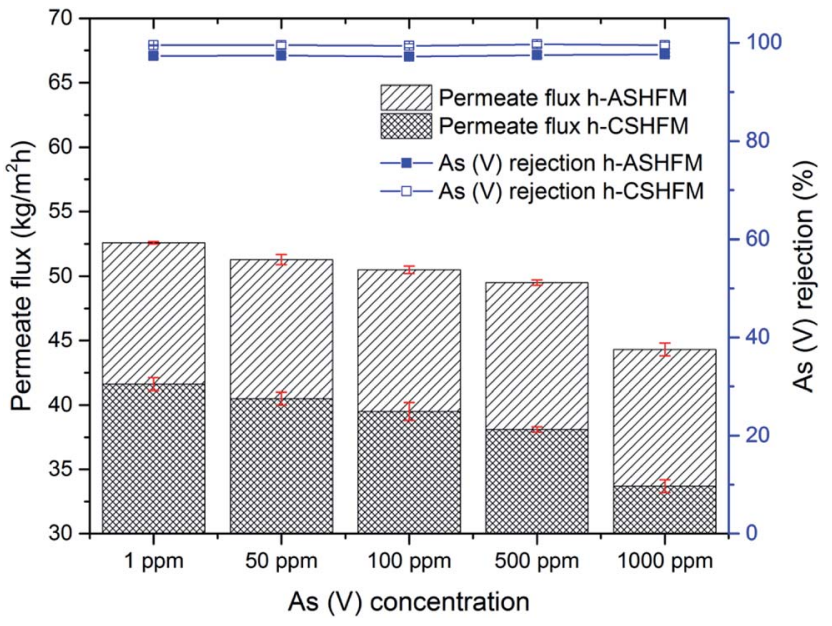

Fig. 7 Effect of As(III) concentration on the permeate flux and As(III) rejection of $\mathrm{h}$-ASHFM and $\mathrm{h}-\mathrm{CSHFM}$ sintered at $1200^{\circ} \mathrm{C}$, during the DCMD process (number of samples, $n=3$; arsenic feed temperature $=$ $60{ }^{\circ} \mathrm{C}$; arsenic $\mathrm{pH}=7.45$ ).

where $C_{\mathrm{m}, \mathrm{f}}$ and $C_{\mathrm{b}, \mathrm{f}}$ are the solute concentrations at the feed membrane interface and the bulk feed solution, respectively, and $\xi_{\mathrm{s}}$ is the concentration polarization coefficient.

Notably, when the feed concentration increases, the concentration polarization decreases. In particular, h-ASHFM has a larger pore size than h-CSHFM, thus leading to a higher yield ${ }^{40}$ In this context, this mechanism enhanced heat losses by conduction and decreased the thermal efficiency of the MD process, thus resulting in decrease of the permeate flux for both h-ASHFM and h-CSHFM. In addition, this phenomenon can be explained by the fact that As(III) is 4-10 times more soluble in water than $\mathrm{As}(\mathrm{v}) .{ }^{41}$ Interestingly, a similar trend in permeate flux was also observed for As(III), as larger than As(v), by Qu et al. ${ }^{\mathbf{4 2}}$ Thus, it was concluded that such a trend is highly likely to be related to the partial wetting phenomenon resulting from larger pores that induce lower LEPw. Taken together, the permeate flux offered in this study is higher than that of a polymeric membrane $\left(2-10 \mathrm{~kg} \mathrm{~m}^{-2} \mathrm{~h}^{-1}\right){ }^{43}$

\subsection{Effect of arsenic feed temperature}

Fig. 8 summarizes the permeate flux of h-CSHFM at feed temperatures of $50,60,70$ and $80{ }^{\circ} \mathrm{C}$, while maintaining the permeate temperature at $15{ }^{\circ} \mathrm{C}$ for 4 hours. The feed concentration was $1 \mathrm{ppm}$. It is interesting to note that increasing the feed temperature from 50 to $80{ }^{\circ} \mathrm{C}$ increased the permeate flux from 30.5 to $50.4 \mathrm{~kg} \mathrm{~m}^{-2} \mathrm{~h}^{-1}$ and 30.2 to $51.3 \mathrm{~kg} \mathrm{~m}^{-2} \mathrm{~h}^{-1}$ for As(III) and As(v), respectively. Such a sharp increase is due to the exponential dependence of the vapor pressure on temperature, as reported in the literature. ${ }^{\mathbf{4 4}} \mathrm{A}$ similar trend was also obtained by most reported studies. ${ }^{\mathbf{4 5 , 4 6}}$ In fact, the transmembrane water vapor pressure difference can be expressed as: ${ }^{47}$

$$
\begin{aligned}
J_{\mathrm{w}} & =B_{\mathrm{w}} \Delta \rho_{\mathrm{w}}=\beta_{\mathrm{w}}\left(\rho_{\mathrm{w}, \mathrm{f}}^{0} \alpha_{\mathrm{w}, \mathrm{f}}-\rho_{\mathrm{w}, \mathrm{p}}^{0} \alpha_{\mathrm{w}, \mathrm{p}}\right) \\
& =\beta_{\mathrm{w}}\left(\rho_{\mathrm{w}, \mathrm{f}}^{0} \gamma_{\mathrm{w}, \mathrm{f}} x_{\mathrm{w}, \mathrm{f}}-\rho_{\mathrm{w}, \mathrm{p}}^{0} \gamma_{\mathrm{w}, \mathrm{p}} x_{\mathrm{w}, \mathrm{p}}\right)
\end{aligned}
$$




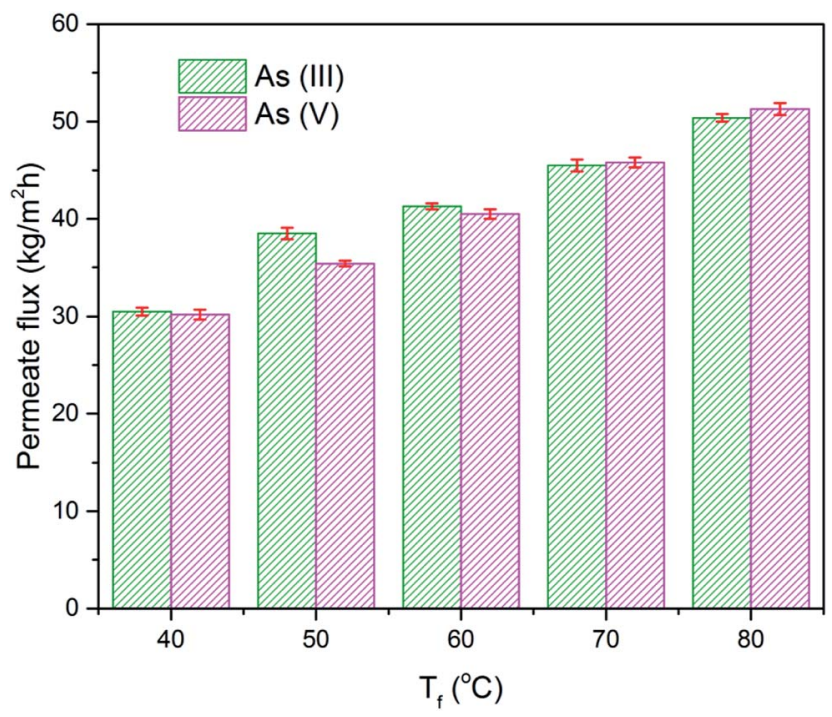

Fig. 8 Effect of feed temperature on the permeate flux of h-CSHFM sintered at $1200{ }^{\circ} \mathrm{C}$, during the DCMD process (number of samples, $n$ $=3$; arsenic concentration $=1 \mathrm{ppm}$; arsenic $\mathrm{pH}=7.45$ ).

where $\beta_{\mathrm{w}}, \alpha_{\mathrm{w}}, \gamma_{\mathrm{w}}$ and $x_{\mathrm{w}}$ are the membrane DCMD coefficient, membrane activity, membrane activity coefficient and mole fraction of water, respectively. The subscripts $w, f$ and $p$ refer to water, feed and permeate, respectively. Thereby, $\beta_{\mathrm{w}}$ is a function of the applied temperature and membrane properties (pore size, porosity, thickness and tortuosity).
Based on eqn (4), the increasing trend of permeate vapor flux is due to the exponential increase in the vapor pressure of the feed aqueous solution with temperature, which enhances the driving force. The water vapor pressure can be determined by means of the Antoine equation ${ }^{47}$ :

$$
P_{\mathrm{w}}{ }^{0}(T)=\exp \left(23.1964-\frac{3816.44}{T-46.13}\right)
$$

For example, when $T=40^{\circ} \mathrm{C}$, permeate flux $\left(P_{\mathrm{w}}\right)=30.5 \mathrm{~kg}$ $\mathrm{m}^{-2} \mathrm{~h}^{-1}$ and $30.2 \mathrm{~kg} \mathrm{~m}^{-2} \mathrm{~h}^{-1}$ for As(III) and As(v), respectively. The permeate flux is then described as: ${ }^{48}$

$$
J_{\mathrm{w}}=B_{\mathrm{w}} \Delta p_{\mathrm{w}}
$$

where $B_{\mathrm{w}}$ is membrane DCMD coefficient, $\Delta p_{\mathrm{w}}$ is partial vapor pressure at the membrane surface. Assuming $B_{\mathrm{w}}$ is 1 , therefore the $\Delta p_{\mathrm{w}}$ is $30.5 \mathrm{~kg} \mathrm{~m}^{-2} \mathrm{~h}^{-1}$ and $30.2 \mathrm{~kg} \mathrm{~m}^{-2} \mathrm{~h}^{-1}$ for As(III) and $\operatorname{As}(\mathrm{v})$, respectively.

Thereby, when $T=80^{\circ} \mathrm{C}$, permeate flux $\left(J_{\mathrm{w}}\right)=50.4 \mathrm{~kg} \mathrm{~m}^{-2}$ $\mathrm{h}^{-1}$ and $51.3 \mathrm{~kg} \mathrm{~m}^{-2} \mathrm{~h}^{-1}$ for $\mathrm{As}(\mathrm{III})$ and $\mathrm{As}(\mathrm{v})$, respectively. Theoretically, increasing the feed temperature will increase the vapor pressure of the feed solution and the driving force. ${ }^{\mathbf{4 9}}$

In this regard, a reasonably good agreement was obtained between the experimental and theoretical DCMD permeate flux calculated through the Antoine equation (5). In fact, it is also advisable to work under high feed temperatures although the effect of temperature polarization is enhanced. ${ }^{47}$ Interestingly, this result reveals that h-CSHFM does not swell although a high
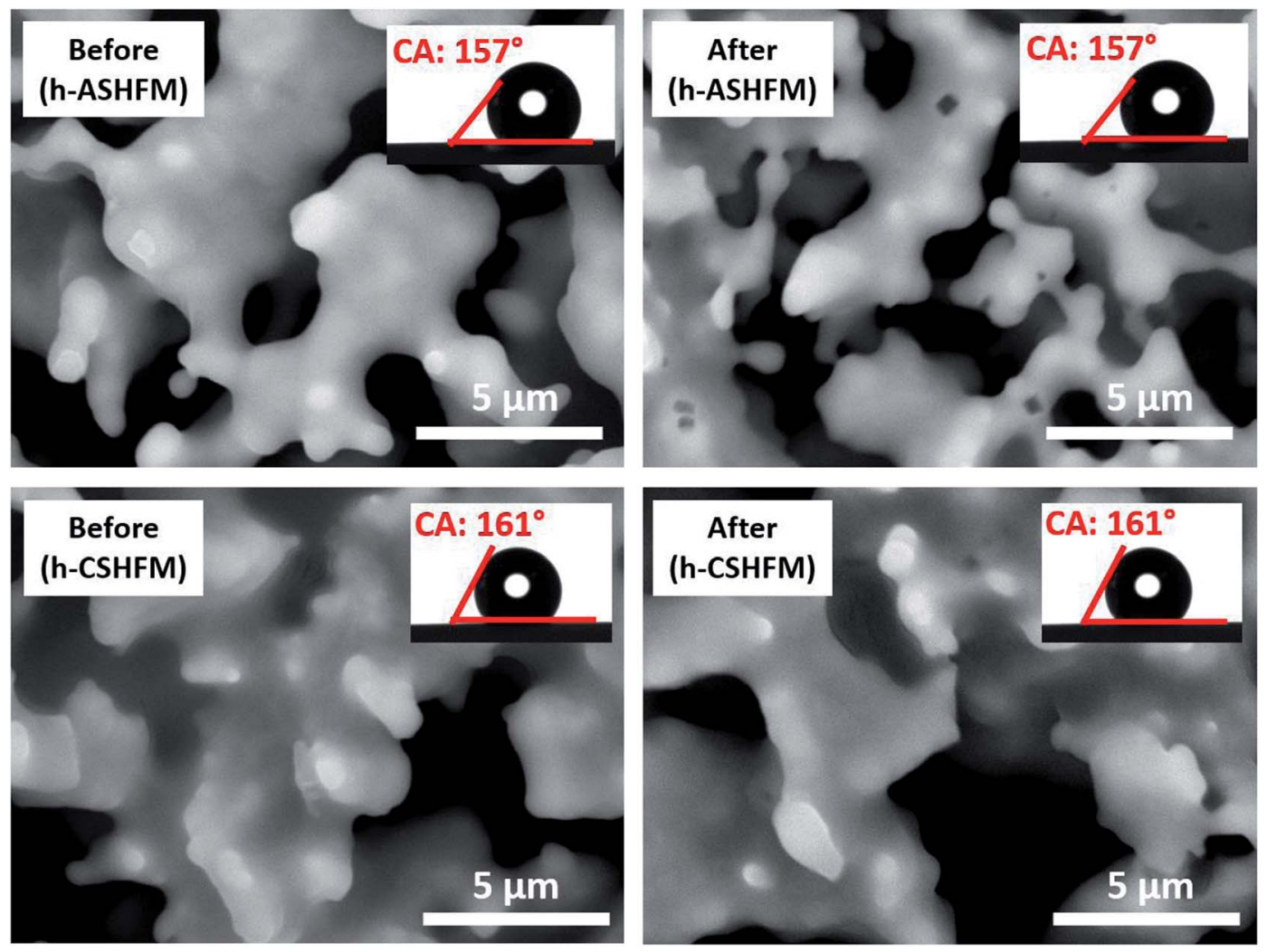

Fig. 9 SEM images of h-ASHFM and h-CSHFM before and after the DCMD process towards arsenic removal. 
temperature of $80^{\circ} \mathrm{C}$ is used during the process (Fig. 9), in contrast to the swelling mechanism previously observed for ceramic membranes prepared from kaolin clay. ${ }^{\mathbf{1 1}}$ Another remarkable result is that the contact angle value observed was not affected by the applied high temperature. It should be mentioned that the permeate flux for the membrane from kaolin clay was decreased due to the clay swelling mechanism at the feed temperature of $80{ }^{\circ} \mathrm{C}^{11}$ which is not noticeable for h-CSHFM in this study. Therefore, it can be concluded that green, ceramic membrane from rice husk waste can solve the problem of membrane swelling.

\section{Conclusions}

Green, ceramic hollow fibre membranes derived from rice husk ash were successfully modified via FAS grafting and evaluated for arsenic removal through the direct contact membrane distillation (DCMD) process by varying the $\mathrm{pH}$ of arsenic, the concentration of arsenic and the arsenic feed temperature for different types of arsenic $[\mathrm{As}(\mathrm{III})$ and $\mathrm{As}(\mathrm{v})]$. When these membranes deal with different $\mathrm{pH}$ values of arsenic, the permeate flux value showed some changes, but with a small gap. Moreover, it is worth mentioning that h-ASHFM and h-CSHFM induce larger values of permeate flux $\left(\sim 55.8 \mathrm{~kg} \mathrm{~m}^{-2} \mathrm{~h}^{-1}\right)$ compared with results from the literature, as they induced a larger membrane pore size. With respect to arsenic rejection, h-CSHFM, with a pore size of $0.5 \mu \mathrm{m}$, exhibited higher rejection, up to $99.6 \%$. In spite of this, h-ASHFM cannot reject As(III) and As(v) to the MCL value of $10 \mathrm{ppb}$ due to the larger membrane pore size $(1.2 \mu \mathrm{m})$, which led to a partial wetting phenomenon. In particular, the permeate flux decreased when arsenic concentration increased due to the decrease in concentration polarization. However, h-CSHFM was able to reject arsenic to the MCL. Therefore, it is concluded that the optimum membrane pore size for the MD system is in the range of $0.5 \mu \mathrm{m}$. Interestingly, h-CSHFM was able to withstand high temperatures of $80{ }^{\circ} \mathrm{C}$ for the DCMD process for 4 hours operation.

\section{Conflicts of interest}

There are no conflicts to declare.

\section{Acknowledgements}

The authors gratefully acknowledge financial support from the Ministry of Education Malaysia under the Higher Institution Centre of Excellence Scheme (Project Number: R.J090301.7846.4J192), Universiti Teknologi Malaysia under the Research University Grant Tier 1 (Project number: Q.J130000.2546.16H40) and The Hitachi Global Foundation via Hitachi Scholarship Research Support Program 2018 awarded to the corresponding author. The authors would also like to thank Research Management Centre, Universiti Teknologi Malaysia for technical support.

\section{References}

1 P. L. Smedley and D. G. Kinniburgh, A review of the source, behaviour and distribution of arsenic in natural waters, Appl. Geochem., 2002, 17, 517-568.
2 M. Bissen and F. H. Frimmel, Arsenic - a Review. Part I: Occurrence, Toxicity, Speciation, Mobility, Acta Hydrochim. Hydrobiol., 2003, 31, 9-18.

3 C.-S. Fan, S.-C. Tseng, K.-C. Li and C.-H. Hou, Electroremoval of arsenic(III) and $\operatorname{arsenic(V)}$ from aqueous solutions by capacitive deionization, J. Hazard. Mater., 2016, 312, 208-215.

4 P. Pal, Groundwater Arsenic Remediation: Treatment Technology and Scale UP, Elsevier Science, 2015.

5 A. Basu, D. Saha, R. Saha, T. Ghosh and B. Saha, A review on sources, toxicity and remediation technologies for removing arsenic from drinking water, Res. Chem. Intermed., 2014, 40, 447-485.

6 D. Mohan and C. U. Pittman Jr, Arsenic removal from water/ wastewater using adsorbents-A critical review, J. Hazard. Mater., 2007, 142, 1-53.

7 F. Macedonio and E. Drioli, Pressure-driven membrane operations and membrane distillation technology integration for water purification, Desalination, 2008, 223, 396-409.

$8 \mathrm{M}$. Khayet and T. Matsuura, Chapter 1 - Introduction to Membrane Distillation, Membrane Distillation, Elsevier, Amsterdam, 2011, pp. 1-16.

$9 \mathrm{M}$. Khayet, Membranes and theoretical modeling of membrane distillation: A review, Adv. Colloid Interface Sci., 2011, 164, 56-88.

10 S. K. Hubadillah, M. H. D. Othman, T. Matsuura, M. A. Rahman, J. Jaafar, A. F. Ismail and S. Z. M. Amin, Green silica-based ceramic hollow fiber membrane for seawater desalination via direct contact membrane distillation, Sep. Purif. Technol., 2018, 205, 22-31.

11 S. K. Hubadillah, M. H. D. Othman, A. F. Ismail, M. A. Rahman and J. Jaafar, A low cost hydrophobic kaolin hollow fiber membrane (h-KHFM) for arsenic removal from aqueous solution via direct contact membrane distillation, Sep. Purif. Technol., 2018.

12 M. S. El-Bourawi, Z. Ding, R. Ma and M. Khayet, A framework for better understanding membrane distillation separation process, J. Membr. Sci., 2006, 285, 4-29.

13 D. Wang, K. Li and W. K. Teo, Preparation and characterization of polyvinylidene fluoride (PVDF) hollow fiber membranes, J. Membr. Sci., 1999, 163, 211-220.

14 M. R. Jamalludin, Z. Harun, S. K. Hubadillah, H. Basri, A. F. Ismail, M. H. D. Othman, M. F. Shohur and M. Z. Yunos, Antifouling polysulfone membranes blended with green $\mathrm{SiO} 2$ from rice husk ash (RHA) for humic acid separation, Chem. Eng. Res. Des., 2016, 114, 268-279.

15 S. Mansur, M. H. D. Othman, A. F. Ismail, S. H. Sheikh Abdul Kadir, F. Kamal, P. S. Goh, H. Hasbullah, B. C. Ng and M. S. Abdullah, Investigation on the effect of spinning conditions on the properties of hollow fiber membrane for hemodialysis application, J. Appl. Polym. Sci., 2016, 133.

16 M. Z. Zailani, A. F. Ismail, S. H. Sheikh Abdul Kadir, M. H. D. Othman, P. S. Goh, H. Hasbullah, M. S. Abdullah, B. C. $\mathrm{Ng}$ and F. Kamal, Hemocompatibility evaluation of poly(1,8-octanediol citrate) blend polyethersulfone 
membranes, J. Biomed. Mater. Res., Part A, 2017, 105, 15101520.

17 N. Said, H. Hasbullah, A. F. Ismail, M. H. D. Othman, P. S. Goh, M. N. Zainol Abidin, S. H. Sheikh Abdul Kadir, F. Kamal, M. S. Abdullah and B. C. Ng, Enhanced hydrophilic polysulfone hollow fiber membranes with addition of iron oxide nanoparticles, Polym. Int., 2017, 66, 1424-1429.

18 M. N. Z. Abidin, P. S. Goh, A. F. Ismail, M. H. D. Othman, H. Hasbullah, N. Said, S. H. S. A. Kadir, F. Kamal, M. S. Abdullah and B. C. Ng, Antifouling polyethersulfone hemodialysis membranes incorporated with poly (citric acid) polymerized multi-walled carbon nanotubes, Mater. Sci. Eng., C, 2016, 68, 540-550.

19 M. N. Z. Abidin, P. S. Goh, A. F. Ismail, M. H. D. Othman, H. Hasbullah, N. Said, S. H. S. A. Kadir, F. Kamal, M. S. Abdullah and B. C. Ng, Development of biocompatible and safe polyethersulfone hemodialysis membrane incorporated with functionalized multi-walled carbon nanotubes, Mater. Sci. Eng., C, 2017, 77, 572-582.

20 L. Li, M. Chen, Y. Dong, X. Dong, S. Cerneaux, S. Hampshire, J. Cao, L. Zhu, Z. Zhu and J. Liu, A low-cost alumina-mullite composite hollow fiber ceramic membrane fabricated via phase-inversion and sintering method, J. Eur. Ceram. Soc., 2016, 36, 2057-2066.

21 S. K. Hubadillah, M. H. D. Othman, T. Matsuura, A. F. Ismail, M. A. Rahman, Z. Harun, J. Jaafar and M. Nomura, Fabrications and applications of low cost ceramic membrane from kaolin: A comprehensive review, Ceram. Int., 2018, 44, 4538-4560.

22 M. R. Jamalludin, Z. Harun, M. H. D. Othman, S. K. Hubadillah, M. Z. Yunos and A. F. Ismail, Morphology and property study of green ceramic hollow fiber membrane derived from waste sugarcane bagasse ash (WSBA), Ceram. Int., 2018, 44, 18450-18461.

23 A. Norfazliana, A. R. Mukhlis, O. Mohd Hafiz Dzarfan, A. F. Ismail, J. Juhana and A. A. Azian, Preparation and characterization of self-cleaning alumina hollow fiber membrane using the phase inversion and sintering technique, Ceram. Int., 2016, 42, 12312-12322.

24 C. Ren, H. Fang, J. Gu, L. Winnubst and C. Chen, Preparation and characterization of hydrophobic alumina planar membranes for water desalination, J. Eur. Ceram. Soc., 2015, 35, 723-730.

25 Z. Shi, Y. Zhang, C. Cai, C. Zhang and X. Gu, Preparation and characterization of $\alpha$-Al2O3 hollow fiber membranes with four-channel configuration, Ceram. Int., 2015, 41, 13331339.

26 Z. Harun, S. K. Hubadillah, S. Hasan and M. Z. Yunos, Effect of thermodynamic properties on porosity of ceramic membrane prepared by phase inversion, Appl. Mech. Mater., 2014, 575, 31-35.

27 J.-H. Eom, H.-J. Yeom, Y.-W. Kim and I.-H. Song, Ceramic membranes prepared from a silicate and clay-mineral mixture for treatment of oily wastewater, Clays Clay Miner., 2015, 63, 222-234.
28 G. M. K. Tolba, A. M. Bastaweesy, E. A. Ashour, W. Abdelmoez, K. A. Khalil and N. A. M. Barakat, Effective and highly recyclable ceramic membrane based on amorphous nanosilica for dye removal from the aqueous solutions, Arabian J. Chem., 2016, 9, 287-296.

29 N. Saffaj, N. El Baraka, R. Mamouni, H. Zgou, A. Laknifli, S. Alami Younssi, Y. Darmane, M. Aboulkacem and O. Mokhtari, New bio ceramic support membrane from animal bone, J. Microbiol. Biotechnol. Res., 2013, 3, 1-6.

30 S. K. Hubadillah, M. H. D. Othman, A. F. Ismail, M. A. Rahman, J. Jaafar, Y. Iwamoto, S. Honda, M. I. H. M. Dzahir and M. Z. M. Yusop, Fabrication of low cost, green silica based ceramic hollow fibre membrane prepared from waste rice husk for water filtration application, Ceram. Int., 2018, 44, 10498-10509.

31 S. K. Hubadillah, M. H. D. Othman, M. A. Rahman, A. F. Ismail and J. Jaafar, Preparation and characterization of inexpensive kaolin hollow fibre membrane (KHFM) prepared using phase inversion/sintering technique for the efficient separation of real oily wastewater, Arabian J. Chem., 2018.

32 A. Fritsch, G. R. Willmott and M. Taylor, Superhydrophobic New Zealand leaves: contact angle and drop impact experiments, J. R. Soc. N. Z., 2013, 43, 198-210.

$33 \mathrm{~V}$. Kapsali, 5 - Biomimetic principles for design of water repellent surfaces, ed. J. Williams, in Waterproof and Water Repellent Textiles and Clothing, Woodhead Publishing, 2018, pp. 121-135.

34 M. A. Abdulhameed, M. H. D. Othman, A. F. Ismail, T. Matsuura, Z. Harun, M. A. Rahman, M. H. Puteh, J. Jaafar, M. Rezaei and S. K. Hubadillah, Carbon dioxide capture using a superhydrophobic ceramic hollow fibre membrane for gas-liquid contacting process, J. Cleaner Prod., 2017, 140, 1731-1738.

35 C. Picard, A. Larbot, E. Tronel-Peyroz and R. Berjoan, Characterisation of hydrophilic ceramic membranes modified by fluoroalkylsilanes into hydrophobic membranes, Solid State Sci., 2004, 6, 605-612.

36 N. Aissaoui, L. Bergaoui, J. Landoulsi, J.-F. Lambert and S. Boujday, Silane Layers on Silicon Surfaces: Mechanism of Interaction, Stability, and Influence on Protein Adsorption, Langmuir, 2012, 28, 656-665.

37 A. Alkhudhiri, N. Darwish and N. Hilal, Membrane distillation: A comprehensive review, Desalination, 2012, 287, 2-18.

38 E. Curcio and E. Drioli, Membrane Distillation and Related Operations-A Review, Sep. Purif. Rev., 2005, 34, 35-86.

39 M. K. Souhaimi and T. Matsuura, Membrane Distillation: Principles and Applications, Elsevier Science, 2011.

40 J. R. Werber, A. Deshmukh and M. Elimelech, The Critical Need for Increased Selectivity, Not Increased Water Permeability, for Desalination Membranes, Environ. Sci. Technol. Lett., 2016, 3, 112-120.

$41 \mathrm{P}$. Pal and A. K. Manna, Removal of arsenic from contaminated groundwater by solar-driven membrane distillation using three different commercial membranes, Water Res., 2010, 44, 5750-5760. 
42 D. Qu, J. Wang, D. Hou, Z. Luan, B. Fan and C. Zhao, Experimental study of arsenic removal by direct contact membrane distillation, J. Hazard. Mater., 2009, 163, 874-879.

43 A. Criscuoli, P. Bafaro and E. Drioli, Vacuum membrane distillation for purifying waters containing arsenic, Desalination, 2013, 323, 17-21.

44 V. Belessiotis, S. Kalogirou and E. Delyannis, Chapter Four Membrane Distillation, ed. V. Belessiotis, S. Kalogirou and E. Delyannis, in Thermal Solar Desalination, Academic Press, 2016, pp. 191-251.

45 G. Amy, N. Ghaffour, Z. Li, L. Francis, R. V. Linares, T. Missimer and S. Lattemann, Membrane-based seawater desalination: Present and future prospects, Desalination, 2017, 401, 16-21.
46 A. Boubakri, S. A.-T. Bouguecha, I. Dhaouadi and A. Hafiane, Effect of operating parameters on boron removal from seawater using membrane distillation process, Desalination, 2015, 373, 86-93.

47 M. Khayet and T. Matsuura, Chapter 10 - Direct Contact Membrane Distillation, Membrane Distillation, Elsevier, Amsterdam, 2011, pp. 249-293.

48 J. Phattaranawik, R. Jiraratananon and A. G. Fane, Heat transport and membrane distillation coefficients in direct contact membrane distillation, J. Membr. Sci., 2003, 212, 177-193.

49 Y. Xuesheng and W. Caiyun, Experimental study on vacuum membrane distillation based on brine desalination by PVDF, IOP Conference Series: Earth and Environmental Science, 2017, vol. 67, p. 012002. 